This item was submitted to Loughborough's Research Repository by the author.

Items in Figshare are protected by copyright, with all rights reserved, unless otherwise indicated.

\title{
The engagement agenda, multimedia learning and the use of images in higher education lecturing: or, how to end death by PowerPoint
}

PLEASE CITE THE PUBLISHED VERSION

http://dx.doi.org/10.1080/0309877X.2017.1332356

\section{PUBLISHER}

(c) UCU. Published by Taylor \& Francis

\section{VERSION}

AM (Accepted Manuscript)

\section{PUBLISHER STATEMENT}

This work is made available according to the conditions of the Creative Commons Attribution-NonCommercialNoDerivatives 4.0 International (CC BY-NC-ND 4.0) licence. Full details of this licence are available at: https://creativecommons.org/licenses/by-nc-nd/4.0/

\section{LICENCE}

CC BY-NC-ND 4.0

\section{REPOSITORY RECORD}

Roberts, David. 2019. "The Engagement Agenda, Multimedia Learning and the Use of Images in Higher Education Lecturing: Or, How to End Death by Powerpoint”. figshare. https://hdl.handle.net/2134/23235. 


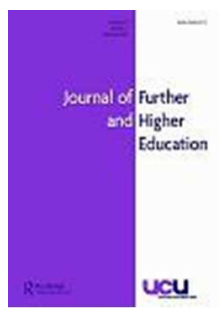

The Engagement Agenda, Multimedia Learning and the use of images in HE lecturing:

\begin{tabular}{|r|l|}
\hline Journal: & Journal of Further and Higher Education \\
\hline Manuscript ID & CJFH-2016-0093.R4 \\
\hline Manuscript Type: & Original Paper \\
\hline Keywords: & Lectures, Engagement, Understanding, Images, Multimedia Learning \\
\hline \multicolumn{2}{|}{} \\
\hline
\end{tabular}

SCHOLARONE ${ }^{\text {m }}$

Manuscripts 
The Engagement Agenda, Multimedia Learning and the use of images in HE lecturing: Or, how to end Death by PowerPoint.

6564 words, excluding bibliography 


\title{
Multimedia and images in HE lecturing
}

\begin{abstract}
This article is concerned with student engagement and understanding in large group teaching in Higher Education (HE). Specifically, it is concerned with the application of Multimedia Learning (MML) methods in Politics, History, International Relations, Sociology, Social Work, and Business and Economics teaching that privilege the use of images to complement text in lecture presentations. This 'visual' method, it is claimed in the literature, generates engagement and understanding better than text alone. This article develops, applies and empirically tests with students, MML methods across a range of Higher Education disciplines over three years. The research deploys Participatory Action Research (PAR) methods engaging students as active agents of investigation and change. It finds evidence to support the hypothesis that apposite images combined with reduced text increases students' engagement and understanding with academic content, but that much formal research needs to expand on the range of demographics tested.
\end{abstract}

Key words: Lectures; engagement; understanding; images; multimedia learning

\section{Engagement}

This article concerns how we might improve students' engagement with their academic studies in large group lectures. It concerns 'individual student learning' specific to pedagogy (Trowler, 2010, p. 10; Gibbs, 2010). Trowler's three 'dimensions' further frame this study. Engagement is treated as necessarily involving behavioural, emotional and cognitive elements in conjunction. Behavioural engagement involves non-disruptive attendance, for example. Emotional engagement involves affective responses including 'interest and enjoyment'. Cognitive engagement involves students being 'invested in their learning', for instance (2010, p. 6). This paper addresses Multimedia Learning (MML) and specifically the use of images in large group lectures as a way of engendering student pedagogic engagement. The next section briefly reviews how wider global socio-technological evolutions frame MML's evolution and substantiate the rationale for deploying this literature in relation to academic engagement and understanding. I follow this with a discussion of the claimed value of MML methods, and a description of the pedagogic method I developed from that literature to test those claims. I then present data from tests I conducted with students from a wide range of disciplines over three years.

Rise of the digital

Peter Felten refers to a 'pictorial turn' (2008, p. 60) in human history. The rise of digital representation and communication of information, coupled with the emergence and growth of the Internet, has led to the inexorable production, storage, dissemination and consumption of digital images. A variety of non-peer reviewed sources claim that Facebook alone hosted in 2013 a quarter of a trillion images. A multitude of other hosting platforms carry billions of 
visual creations made by amateurs and professionals alike. Photography has been transformed into a faster and cheaper method that documents and represents planetary existence. Digital data banks have proliferated to buy, control, market and sell images to billions of consumers. Movies, news, mini-series and sport are carried globally through digital networks. Louis Tietje and Steven Cresap conclude that:

Visual media... are the main means of communication and expression in postmodern culture. Image-producing industries have taken on... surprising cultural legitimacy (2005).

According to Professor Emeritus Merlin Donald, these 'digital media are the new interface between mind and world' (2014). Julie Coates argues that this generation is 'the most visual of all learning cohorts' (2006, p. 126). It is this visual, digital context in which HE institutions presently compete. Tietje and Cresap argue that academia is 'marketed overwhelmingly to... young adults [for whom] visual media dominate’ (2005). Our students are Eva Brumberger's 'Millennial Learners' (2011; Jones, et al., 2010), but for the most part, the academics teaching them hail from and rely on another era's ways. In other words, the supply of Learning and Teaching (L\&T) may be momentarily out of synch with demand. Whilst Ellen Helsper and Rebecca Eynon argue that older academics are more than able to learn to use contemporary visual instruments of pedagogy (2010), it is often the case that we do not (Oblinger \& Oblinger, 2005; Tuckey \& Selvaratnam, 1993). When we do, we tend to use them supportively and occasionally, rather than as routine means in themselves to convey complex material, data and argument and to engage students.

Instead, our lectures tend to be text- and bullet point-heavy (Schrand, 2008; Little, et al., 2010; Hattwig, et al., 2013). They are eccentrically text-centric in a visual world, perhaps in large part because Microsoft's automatic slide formatting dissuades us from acting otherwise; it privileges format over content. Peter Norvig, Google's then Director of Research, went as far as to suggest that PowerPoint was more dangerous than an AK47 assault rifle, because very bad things can be done with it (Jarvis, 2014, p. 165). Edward Tufte, Emeritus Professor at Yale University, famously quipped that 'Power corrupts, and PowerPoint corrupts absolutely' (2015). It has even been blamed in part for the Colombia shuttle disaster in 2003 (Thompson, 2003; Meira, et al., 2010); and elite western military officers have also expressed their despair at its impact (Yu, 2014). PowerPoint has become 'parodied, disparaged and blamed for failures to communicate clearly' (2007, p. 77). The academy has become concerned (Bumiller, 2010; Hopper \& Waugh, 2014), but not to the extent that this particular elephant in the room has been properly confronted. In the rush to object, however, we should not throw out babies and bathwater; we do not blame Microsoft Word when we read a bad article. If images are key informants of the latest HE generation - and few challenge this claim - then the way we use PowerPoint, Keynote, Prezi and the expanding array of presentation platforms - can be easily 
modified to adapt to the visual era we are presently immersed in. I now turn to why this is the case.

\section{Multimedia Learning (MML)}

Richard Mayer defines MML as a body of research and literature concerned with our capacity for 'building mental representations from words and pictures' (2014, p. 2). MML's operating assumptions revolve around the idea that 'people can learn more deeply from words and pictures than from words alone' $(2014$, p. 1). This is because humans possess 'separate systems for processing pictorial and verbal material' (2003, p. 44). Mayer and others refer to this as 'dual-coding' or 'dual processing'. Nigel Beacham and James Alty tell us that 'one channel processes verbal information such as text and audio and the other channel processes visual information such as diagrams, animations and photographs' (2006, p. 78). Allan Paivio outlines the process in greater detail:

Dual coding involves two distinct subsystems... a verbal system specialized for dealing directly with language, and a nonverbal (imagery) system specialized for dealing with nonlinguistic objects and events (2007, p. 77).

This is important because there is a limit to the amount of information that each channel can process at any one time (Lewis, 2016; Mayer \& Moreno, 2003). John Sweller, Paul Ayres and Slava Kalyuga argue that this dual processing capability means that images, when used in conjunction with words and/or limited text, are better than words on their own. They maintain that:

it is effective to speak to a diagram [graphic], because it presents information in a different form. But it is not effective to speak the same words that are written, because it is putting too much load on the mind and decreases [recipients'] ability to understand what is being presented (2011, p. 112).

Paivio's groundbreaking research in the 1970s and 1980s still informs disciplines concerned with communication, cognition and memory (Paivio, 1971; Paivio, 1986; Beacham \& Alty, 2006; Mayer \& Moreno, 2003). The present argument of MML is that we can use images to convey the meaning of our spoken words. The outcome has been referred to as a Picture Superiority Effect (PSE), whereby we are more likely to understand and remember more, and better, if there are apposite, clear images involved than if there is only text (McBride \& Dosher, 2002; Hockley, 2008; Mayer \& Moreno, 1998). The converse also holds: according to Carol Yue et al, close or 'exact correspondence between on-screen text and narration generally impairs learning' (2013, p. 266). We should not have on the screen, what we are saying. Because audiences cannot easily follow both the spoken and written word simultaneously and, 
since one is normally similar to the other in a lecture, one is redundant (Kosslyn, 2007; Messaris, 1994). It's a double-edged sword: deploying both speech and text simultaneously can reduce learning and engagement because of duplication of message and overload of the cognate capacity to process textual and spoken information in the same area of the brain (Mayer, 2014; Mayer \& Moreno, 2003; Kalyuga \& Sweller, 2014; Lewis, 2016). Presently, PowerPoint users everywhere over-load text as a matter of course. Exceptions are uncommon.

Mayer proposes that since we have the spoken word anyway in a lecture, we could reduce written text in slides and add images that complement, represent, augment or reinforce the spoken words of the presenter. Images for the eyes and words for the ears intuitively makes sense; but it does intellectually as well, according to Mayer's research and that of others (Mayer \& Sims, 1994; Levin, 1981; McKay, 1999). Proponents of dual coding theory argue that 'combining pictures, mental imagery, and verbal elaboration' help learning substantially (1991, p. 163; Lewis, 2016). The message is this: 'People learn better from multimedia messages when they are designed in ways that are consistent with how the human mind works and are consistent with research based principles' (Mayer, 2014, p. 155).

According to a variety of scholars, balancing the load more equitably between auditory and visual processing also reduces pressure on working memory (Clark \& Lyons, 2010; Lewis, 2016). Working memory is comparable to the Random Access Memory (RAM) in a computer (Lewis, 2016). RAM runs software that is being used in the moment and it is limited in size, compared to longer-term storage. Working memory can be understood as 'a cognitive operation in which some bits of information are held in a store characterized by rapid decay in memory while other bits are retrieved from long-term storage' (Siegel \& Ryan, 1989, p. 973; Clark \& Lyons, 2010; Lewis, 2016). It is why we often have trouble remembering long phone numbers but may still recall the toys of our childhoods in detail. Bifurcating intake between images and text reduces cognitive load which in turn increases mental efficiency in the teaching and learning moment.

This scholarship has a substantial heritage, but academia is not the only source of such deliberations. Some members of the business world (below), which HE is frequently invited to emulate in its practices, privilege communication over decoration. That is, whereas there is a plethora of presentation slide templates, fonts, quirky backgrounds, bouncy animations and free downloads with which to titillate an audience, they are just that: titillation. Innovators like Guy Kawasaki and Nancy Duarte argue that unending 'choices' of template design do little or nothing to aid communication of content (Kawasaki, 2012; Duarte, 2008). Instead, these entrepreneurs have taken design and presentation to a different level, combining the 'pictorial turn' with a potent digital platform. Furthermore, major non-governmental bodies like Greenpeace, Oxfam and the Red Cross have similarly adapted to the visual era as a means of conveying complex social issues to a wide audience, generating memorable adverts that reach people's imagination and understanding and affect their thinking (McStay, 2013). 
It is these converging forces - of the enormity of binary globalisation, the emergent positioning of the visual in everyday life, the challenge of engaging and teaching paying students well, the expanding academic research into MML, and the leadership of business in visual communication - which have led to the experiments presented below.

\section{Experiment}

I wanted to know the extent to which digital imagery might help engagement and understanding in undergraduate student lectures, and conducted an experiment over 3 years. There are two elements to this. The first is the development and application of the MML lecture delivery method. The second is the testing of its effects on students.

I have been using the visual method in lectures in a variety of undergraduate modules since 2013. In most academic years I teach 2 modules per semester, all of which use the visual MML method. Subjects and disciplines I teach include Business Studies, International Relations, Politics and History. The total number of students presently exposed to this visual method averages about 225 per week in semester 1 and 90 a week in semester two. The regular curriculum runs in parallel with the testing and research process; volunteers for the research are drawn from the student body I teach weekly.

My lecture slides are about 75\% images (with additional text provided in PowerPoint's 'notes view'). Most of the remaining slides are limited to one line of text, unless lengthy quotes (for example) are valuable. There may be over a hundred slides in a given lecture; but any with text are limited to one line. There is no more material to deliver than if I were doing it the orthodox way. The material is split and distributed to reflect the MML principles outlined above. I use Google and a number of image websites to find images larger than $800 \mathrm{x} 600 \mathrm{~m}$ pixels (for clarity and quality). The images are embedded in the slide background (a 4-click process little different from changing a slide's colour).

Images may be illustrative or metaphorical. Illustrative images can represent an academic issue visually, for example, using the EU flag whilst talking about immigration or Brexit. Any text I want students to have goes in the 'notes view' section. A visual metaphor, on the other hand, is an 'image... used in place of another to suggest an analogy between the two images' (1998, p. 2). Williams suggests that for teaching, a visual metaphor 'should be appropriately simple enough to be easily interpreted, but include enough detail so that the learner can process the metaphor quickly' (1998, p. 3). According to Edward McQuarrie and David Mick, when metaphorical images are easily recognizable, engagement is more active and intense and may evoke more complex cognitive processing than literal images can (1999; Bulmer \& Buchanan, 2006). Some examples follow. 
Image 1 Blood diamond

The 'blood diamond' image accompanied a discussion of the role of capitalism in war.

\section{Image 2 Ape/man}

Ape-man supported a discussion of biological versus social determinism of war.

\section{Image 3 Evolution}

The whole story of evolution, from the sea through DNA to amphibious life to humanity Reproduced with the written permission of the artist, Christophe Kiciak.

Image 4 Inequality. This image helps outline the multiple relationships between richer and poorer.

Image 5 Desertification. This helps render the unfamiliar more recognisable to UK students.

Image 6 Pill. This image supported discussion of marketized healthcare, maternity ward closures and biopolitics.

Image 7 social construction of the mind. This image supports discussion of the social creation of thought.

Image 8 nuclear power industry. Accompanies debate on the safety of nuclear electricity

Image 9 peace and war ontologies. Metaphor for the apparent impotence of peace beliefs to transform the legitimacy of the use of war.

\section{Evaluation}

The extent to which images generated student engagement in lectures drove a mixed method approach, but so too did Trowler's remarks concerning 'a striking absence' of student voices in the engagement debate (2010). My students were to be the subject of the testing I conducted, and were active agents in both methods. The quantitative experiment was derived from Chanlin (1998), McKay (1999) and Kleinman and Dwyer (1999). Their method was to create three groups (one control two test) to compare the delivery of knowledge using no images, then still images and then animation. This was refined to two groups. A control group would view slides with text, and another was exposed to slides with images. The groups were composed of 
volunteers recruited by announcing the project in regular lectures. The number of volunteers varied from year to year (see below for more details) but in all years, male volunteers outnumbered females in both quantitative and qualitative sessions. The gender issue is important and the subject of further inquiry in 2017, particularly because it might be useful to ascertain, given the affective nature of the visual method, whether there is a distinction between how males and females value the visual method.

Both groups were exposed to the same 10-minute PowerPoint presentation on global warming, chosen because of its familiarity to a broad range of students. After each presentation, the students individually completed an online exit survey. The survey questions concerned the effect of the slides, as opposed to asking about text or images.

\section{Focus groups}

The second method of generating feedback involved focus groups, characterised as 'an indepth, open-ended group discussion of 1-2 hours' duration that explores a specific set of issues on a predefined and limited topic' (Robinson, 1999, p. 905). This approach was chosen because whilst the survey method generates statistics, it would not offer explanations. Focus groups encourage 'the production of more fully articulated accounts; and offer an opportunity to observe the process of collective sense-making in action' (Wilkinson, 1998, p. 181; Stewart $\&$ Shamdesani, 2014). Focus group volunteers came from emailing all the student cohort routinely exposed to my lecture method, asking for their involvement. All who did were coopted into the experiment. There now follows a discussion of the first experiments in 2014.

\section{Experiment 1, 2014}

Table 1: quantitative survey responses 2014.

There is a clear trend visible. Group 2 students showed greater cognitive and emotional engagement than Group 1. A higher proportion of students in Group 2 than in Group 1 found the slides encouraged them to think about the material being presented, to understand it and to be emotionally stimulated by it as a precursor to being engaged with the material. This trend was duplicated in the 2015 experiment. The same pattern emerged in all the disciplines tested.

Focus group testing in academic year 2014

The focus group comprised 8 undergraduate students below 21 years of age. They first identified spontaneous critical engagement with images, especially metaphors. These 
'troubled' or 'destabilized' them by forcing them to consider multiple interpretations of an image simultaneously (like the beauty of the diamond juxtaposed with the trauma of the blood). They had no choice but to engage: the images provoked internal confusion in some instances. For one student, the images made 'the concepts come alive', and enabled engagement, attention span and recall.

In line with Joel Levin's (1981) concept of transformational images, students observed that the images to which they were exposed helped them remember what was being taught, partly because well-chosen images do more than represent - they enable students to visualize a connection between two or more concepts. Others said the images made them feel 'invited' into stories (and therefore lecture content). They also said that images 'gave them freedom to interpret [their] subjective meaning' within certain parameters, implying that the learning was more under their control. They could take what they needed to, and were thus empowered in that moment as autonomous learners.

Students found themselves 'concentrating much more' because 'the visual images are stark and unorthodox'. They also 'connect' with the lecture because of an 'emotional reaction' in which students become 'attached' to the image. They added that images can take a student to their own closest experience of what the lecture is discussing. Some suggested that the inevitable subjectivity of images created an important conflict that contributed to their ability to learn. That is, the inherent tension involved in seeing more than one possible meaning to a given image augmented curiosity and critical engagement. Most (7/8) agreed that the tension around the subjectivity of interpretation of the images sometimes made 'study more accessible'.

Use of images also appears to have a relationship with attendance. Whilst 2 students claimed that the images made no difference to their attendance, because they attended all lectures regardless of their format, 6 agreed that the use of images made them 'look forward to the whole experience', adding that 'there is too much to miss' in an image-based lecture. 7 out of the 8 agreed that images 'compel' engagement, in part because the approach 'is new' and means that 'death by PowerPoint' is no longer a fear for them. It was also claimed by 7 of 8 that the images compelled concentration, stimulating engagement and attention.

All this said, the students were quick to point out that there was more to the MML lecture method than simply well-chosen and 'thought-provoking' images. They made it clear that a lecturer's style could influence engagement. They took some time to ponder how this style might be conceptualized or described, concluding in the end that the MML lectures are often a form of story-telling, and that in terms of attention, engagement and comprehension, this cannot easily be separated from the effect of multimedia methods. One student described it as 'performance' but not 'theatre', since the images were part of the art of holding people's attention. It is unlikely this element will be easily separable from an assessment of the effect and utility of MML; but this said, my 'performance' was the same when presenting to both groups. 
A small degree of inference may be drawn between focus groups and the wider cohort routinely exposed to the visual method. First, undemanded feedback by email from students not in the focus groups has reinforced some focus group findings. The primary sentiment in these emails appears to be relief that the slides are not 'drowned' in text, coupled with requests to identify other modules taught this way. Second, it may be worth noting anecdotally that in the modules taught visually, the percentage of 'firsts' for written coursework increased by $60 \%$ between 2013 and 2015 .

\section{Experiment 2, 2015.}

A second experiment was conducted in academic year 2015-2016 with different students studying the same subjects. The test group sample was smaller in 2015, consisting of 7 students only. This change seems not to impact the overall pattern, replicating that of the 2014 data. In terms of cognitive and emotional engagement, Group 2, exposed to full slide images, was more engaged cognitively and emotionally with the presentation in both years. Again, a higher proportion of students in group 2 considered that the slides encouraged them to think about the academic material, to understand it and to be emotionally stimulated by it as a precursor to being engaged with the material.

Table 2: quantitative survey responses 2015.

For 2015, I expanded the range of questions to interrogate the issue of emotional reaction to and connection with the slides. Emotions like 'enjoyment', 'curiosity', 'happiness' and 'sadness' were experienced by those exposed to images that described a subject or conveyed meaning.

Table 3: Extended 2015 quantitative survey questions interrogating emotional reactions.

Focus Group Testing in academic year 2015

I formed another focus group to probe for explanations. This group consisted of 2 males and 1 
female, each under 21. Students say that University non-academic demands on them gave them less time to spare for activities such as this, and this itself has prompted a more critical reflection on the research methods involved. Students talked at length. One claimed that the visual method was 'the most engaging [of all] lectures I've had so far. I haven't missed one yet. You have a connection to an image. You can almost imagine you're there. There's no physical connection to words on a page'. She added that text-only slides failed to:

engage me at all with what [the lecturer is] saying... A lecturer can tell people about things and what [they] mean to people, but when you show them an image, it really drives the point home and made me think about it a lot more.

Another concurred, claiming there was a 'disengagement' with words. He added:

If you just see text saying [in this case] that Agent Orange was used in Viet Nam, you don't connect. But when you see images, that's when you connect. It's the image that resonates. That made me look into it, and I went on to investigate what kind of moral authority had informed US policy makers to place themselves above their own and international laws.

The group agreed that 'if you connect with something emotionally, you're going to remember it outside the lecture. I can recall the content of the year 1 module that had images, but not the others'.

I sought some deeper insight into these students' engagement processes by asking them to think about how such engagement influenced their attention. After discussion, the focus group agreed that:

In any... lecture, different people are going to drop off attention. Having continuous slides of writing isn't going to re-engage you with the lecture, whereas if you hit an emotional chord with images then you are going to be drawn back into the words. In a lot of the other... lectures, I see people leave at half time. I haven't seen that in one of [these] lectures so far. Your lectures get a round of applause. The others don't. I think that says a lot. To be fair, people clap in other lectures, but that's more because they're finished.

A member remarked that:

some of the images really make you think about their meaning. I can't help but be connected to and engaged with the image, and as [the lecturer] discusses its meaning and relevance to the academic 
material, a connection is forged that makes thinking about this stuff a happier experience.

I wanted to understand what was happening for them as they viewed images. Their conclusions were that the engagement, comprehension, attention and learning came from working out the connections between the component parts that created meaning and impact of the image. The images prompted curiosity, and their brains almost involuntarily had to 'puzzle it out'. They referred to one example that had stuck in their minds. Students were divided; some considered it an intellectual stimulant and others abhorred it. According to students, 'it was the subject of debate on and off campus'. One focus group member declared that 'even if someone despises an image, they validate its use by discussing it afterwards, and they're doing exactly what the lecturer wants - engaging in debate'.

I switched focus to the other aspect of this 'flipping' of how I deliver lectures. I asked the students what it meant to them to reduce the visible text on screen (in conjunction with adding images). They answered that it meant they could listen to the lecture and did not have to choose between writing it down or listening. One said it was like the difference between watching a foreign language movie and needing to read the subtitles, and not needing to read them because you understand the language. They could explore the visual and the audio, without having to divert attention to distracting text. A focus group member declared that he would 'rephrase the image textually', interpreting its meaning whilst able still to listen to the lecturer. He added that 'when I'm listening to a voice and watching a picture, I'm not scribbling down the slide text we get anyway on [the Moodle]'.

Another student said that 'text and spoken words force a choice'. This view reflects the scholarship outlined earlier in this article, concerning the problem of overloading cognate capacity. One student then added that 'looking at the images, instead of text, makes me ask, what should I write down, as opposed to accepting the text on a slide and/or copying it down uncritically, which is like A-levels'. Another added that 'images up the ante and give me autonomy, make me active in the lecture, instead of text that spoon-feeds me'. This was to reappear in other disciplines' focus groups.

The focus group all but despaired of text-heavy slides. One declared that when confronted with such slides, which was normal, 'I give up. I don't bother reading it. I miss it. It's a waste of my time. Why am I here?' To broad concurrence, he added that in such circumstances,

I have to make a choice. Am I going to listen to the lecturer, or am I going to read the text he's providing? Half of a lecture is wasted if I have to choose. I can't read the text and listen as well. [Privileging] images, the words complement the image or the image complements the words, instead of me having to pick or choose. 
Widening the net: engaging with other disciplines

Up to 2015, student participants had come from International Relations, History, Politics, Geography, Sociology, Languages and Social Work. I repeated the exercise with students taking Business Studies, Economics, Marketing, Finance and Accounting. The same method was applied again using global warming as the topic, with 45 volunteers aged 18-24, of which 25 (M8/F17) viewed a traditional presentation and 20 (M9/F11) viewed the image-based variant. However, there was a departure in the formation of this group that warrants discussion. To increase the number of respondents, I discussed with students how I might garner more participation. Two methods were proposed. One involves putting videos of the 10 -minute presentation online with a link to the survey on a single page website. The site link would be disseminated through the university, put on Facebook pages, hosted at other institutions and so on. The link to the two videos of the presentations would use a mutating URL to randomize participation. A working test version is visible here. When I tested it, this method doubled participation with one attempt through one Facebook page.

The second suggestion coming from student consultation involves financial incentivization. Cash incentives are used successfully in most areas of the social sciences, including pedagogic research (Halpern, 2011). Nonetheless, for some, incentivization raises ethical questions. Even though it is now a norm to incentivize in scholarly research (Largent, et al., 2012; Sonderholm, 2010; Gächter \& Renner, 2010), it raises complex questions about consent, in line with the Nuremberg Code of 1947. However, administered in accordance with institutional ethical consent parameters developed in accordance with HE best practice conventions, it should present no serious ethical problems, according to David Wendler et al (2002), and Eleanor Singer (2003). In terms of the quality of response, this is more significant, given that earlier groups were not incentivized and the final group was. But an extensive meta-review of the literature revealed that 'relatively few studies have evaluated the effect of incentives on quality of response [and] most studies that have done so have found no effects' (Singer \& Ye, 2013, p. 134). Furthermore, the students in the latter group were told that the research was about ways to improve their own experience of being taught, as had the other groups. I proceeded on this basis. Funding came from the School of Business and Economics (SBE) at Loughborough University, and each student was paid $£ 10$, in line with other institutions' practices.

The results were in line with earlier testing, with image-based slides being preferred by students. Importantly, the elevation of emotional interest was claimed to enhance engagement with the slides and the lecture. One Business Studies student remarked in unsolicited discussion that "the use of pictures and a few words thoroughly helps - when typing up my notes from the lecture, the images you use suddenly appear in my head and as a whole, the method enables a much deeper understanding of the topic'.

Table 4 Business Studies Students Results March 2016 


\begin{abstract}
Focus Group Testing in academic year 2015
I created a 6-student focus group, roughly equally gender represented and all under 21 . A key issue that became apparent was the relationship between the students and the images, and it should be called a relationship because it involved connection, emotions and meaning. But it was also about the relationship between students and lecturers. The students claimed that too many lectures involved academics on 'send' and students on 'receive', engendering a passive disconnect via the slides containing text. Images affected this relationship in two ways. First, the focus group participants agreed that
\end{abstract}

it's nearly impossible to be engaged in that kind of a

setting. But images transform that: I'm drawn to the images

but not the text on the slides. Text is something I just have

to somehow copy. Images I can actually feel enjoyment about.

The group agreed that 'the images stimulate an emotional response. By having that response to the images, you are engaged'. Further, 'an emotional connection [to the lecture subject] can then be backed up with other information, as opposed to having to first warm towards whatever is being presented verbally or with text'. For one student, 'images trigger a reaction that makes me want to pay more attention to the words and text'. For another, images make a subject more real. She said:

You can imagine the situation being described, rather than having just text. The picture makes the topic real, and the words are easier to attach to something I can see has real form. It makes me more receptive to the spoken words of the lecturer. I can relate the information to something concrete I have been shown.

Students felt connected to the images, and thence the subject, and therefore wanted to hear more from the lecturer. The images might be considered as hooks: they generate engagement and interest, to which a lecturer can add and build on.

A second way in which images affect the relational dynamic between students, subjects and staff is that 'images represent an opportunity for a substandard lecturer to have a chance'. The focus group concurred that lecturer quality is uneven, as one would reasonably expect. The group agreed that 'not everyone is a great orator, or speaks clearly, or holds people's attention'. To compensate for this, they suggested that lecturers would 'have a better chance of holding 
our attention by using images'. They added that 'if it's just text, it takes a very good lecturer to get you engaged, whereas a picture allows less gifted lecturers to get your attention'. They qualified this carefully, adding that 'it is possible to have just text on slides and be engaged, but it's very rare and takes someone who has a lot of charisma'. Images, it appears, could be a foundation in which academic text and speech could be embedded, to help alleviate poor quality teaching.

The conversation widened unpredictably into a domain I had not considered. Some students recalled particular images and said that 'they made me have an opinion on the topic, and slides with text rarely do that. With text, I might just be focused on taking down what the lecturer is saying. I am not connected to the subject; I'm just recording words'. But the images created a connection to other aspects of the students' lives. Students observed that 'when there's a picture, you understand the topic better because it has visualized something complicated into a format you can relate to'. They were speaking to Williams' notion (op. cit) whereby one image reflects a conceptually and visually analogous comparison to another. To broad agreement, it was proposed that 'images help connect you to memories of films' and other visual media, as well as to their own experiences and contexts. Given the 'pictorial turn' outlined earlier, and the preponderance and normality of imagery in the construction of their pre-university lives, this is an important extension of connections: from a metaphorical image in a lecture not just to a lived experience but also to other visual media.

This led me to query the relative value of illustrative and figurative images. My assumption had been that metaphorical images would be considered of greater value, since they appear to assist a greater intellectual leap than a solely illustrative one. But some considered that using illustrative images involves a multiplier effect. It removes the banks of text that characterise lecture slides, which can overload cognitive processing. This mirrors Mayer's propositions regarding overloading of cognate capacity with text while under-exploiting image processing capacity. But beyond this remark, the group mostly favoured metaphorical images. They concurred that they 'remember the metaphor ones because they have linked elements that force [them] to connect the components of the image and therefore the metaphor'. They expanded on this by adding that 'creating a chain of things gives my mind structure to follow the argument or explanation the metaphor presents'. It was clear from this group, and the other focus groups, that 'a metaphor and a paradox puzzle you, forcing engagement out of curiosity or just surprise'. But lest babies be thrown out with bathwater, illustrative images can be crucial to some students. 'I'd never seen a picture of desertification. I had no idea it looked like that. I could understand why it would be seen as a threat'. After I asked the students to rank the reasons for favouring images in slides, they concluded that 'the most valuable aspect of using images is that they were thought provoking. They engaged [our] brains with the lecture and helped [us] understand the subject'.

\section{Conclusion}

The rise of images in the digital era is inescapable, as is our students' exposure to them as a 
normal means of communication. Yet the academy remains wedded to an eccentric textcentricity quite at odds with the world beyond the ivory silo. It does not mean a proposition to end textual literacy and it does not propose that all text disappears from lecture slides. It suggests instead that we can combine high-quality, large images with reduced text when we lecture. There is a very sound pedagogic rationale for this conceptual breach to be found in our understanding of cognitive loading, which for some leading scholars means that how we often use PowerPoint may be substantially counter-productive, pedagogically.

The positive outcomes in engagement and understanding are a result of two processes combining to create a third. Text reduction decreases pressure on short term memory and mental processing. Images leverage visual processing into the space vacated in our short-term memory by reduced text. Bifurcation of the information flow (images and limited text) splits the message more equitably between two parallel processing capacities instead of overloading one. The evidence gathered from testing MML theory by introducing representative and metaphoric images across multidisciplinary undergraduate degrees over a three-year period, suggests that students exposed to this form of MML were more engaged and interested, more connected emotionally, and better able to understand complex social issues and processes. MML theory holds up well in this longitudinal multidisciplinary test of its propositions. But the samples in some of the groups were too small to base firm conclusions on. In discussion with some of the students, a website was created to capture remote participation. In addition, a national Community of Practice has also been established to test and extend the experiment in different demographics.

There is more research to be conducted, especially regarding other demographies, neurodiverse groups, and the relationship between visual reception, emotional reaction and mental comprehension. But in short, MML helps students see what we mean through the medium of imagery - and makes their engagement and understanding observably better in the process. The message is the medium and the medium is the message, to paraphrase Marshall McLuhan. 
I would like to acknowledge the support of Professor Helen Drake for her support in the development and testing of this visual method of teaching. 


\section{Works Cited}

Adams, C., 2006. PowerPoint, habits of mind, and classroom culture. Journal of Curriculum studies, 38(4), pp. 389-411.

Beacham, N. \& Alty, J., 2006. An investigation into the effects that digital have on the learning outcomes of individuals who have dyslexia. Computers and Education, 47(1), p. 74-93.

Brumberger, E., 2011. Visual Literacy and the Digital Native: An Examination of the Millennial Learner. Journal of Visual Literacy, 30(1), pp. 19-47.

Bulmer, S. \& Buchanan, M., 2006. Visual rhetoric and global advertising imagery. Journal of Marketing Communications, 12(1), pp. 49-61.

Bumiller, E., 2010. We have met the enemy and he is PowerPoint, New York: New York Times.

Chanlin, L., 1998. Animation to teach students of differing knwledge levels. Journal of Instructional Psychology, 25(3), pp. 166-175.

Clark, R. \& Lyons, C., 2010. Graphics for Learning: Proven Guidelines for Planning, Designing, and Evaluating Visuals in Training Materials. Oxford: Wiley.

Coats, J., 2006. Generational learning styles. River Falls, Wisconsin: LERN.

Donald, M., 2014. The Digital Era: Challenges for the Modern Mind. CADMUS, 2(2), pp. 68-79 .

Duarte, N., 2008. Slide:ology: The Art and Science of Creating Great Presentations. Sebastapol, Ca: O'Reilly Media.

Felten, P., 2008. Visual Literacy. Change: The Magazine of Higher Learning, 40(6), pp. 60-64.

Gächter, S. \& Renner, E., 2010. The effects of (incentivized) belief elicitation in public goods experiments. Experimental Economics, 13(3), pp. 364-377.

Gibbs, G., 2010. Dimensions of Quality, York: Higher Education Academy.

Gibbs, G., 2014. Student engagement, the latest buzzword. Times Higher Education, 1 May.

Halpern, S., 2011. Financial Incentives for Research Participation: Empirical Questions, Available Answers and the Burden of Further Proof. American Journal of the Medical Sciences, 342(4), pp. 290293.

Hattwig, D., Bussert, K., Medaille, A. \& Burgess, J., 2013. Visual Literacy Standards in Higher Education: New Opportunities for Libraries and Student Learning. Portal: Libraries and the Academy Project MUSE. Web. 29 Jul. 2016, 13(1), pp. 61-89.

Helsper, E. \& Eynon, R., 2010. Digital natives: where is the evidence?. British Educational Research Journal, 36(3), pp. 503-520.

Hockley, W., 2008. The picture superiority effect in associative recognition. Memory \& Cognition, 36(7), pp. 1351-1359. 
Hopper, K. \& Waugh, J. B., 2014. PowerPoint: An overused technology deserving of criticism but indispensible. Educational Technology: the magazine for managers of change in education, Volume September-October, pp. 29-34.

Jarvis, M., 2014. Brilliant Ideas for Using ICT in the Classroom : A very practical guide for teachers and lecturers. London: Routledge.

Jones, C., Ruslan, R., Cross, S. \& Healing, G., 2010. Net generation or Digital Natives: Is there a distinct new generation entering university?. Computers and Education, 54(3), pp. 722-732.

Kalyuga, S. \& Sweller, J., 2014. The redundancy principle in multimedia learning.. In: R. Mayer, ed. The Cambridge Handbook of Multimedia Learning. Cambridge: Cambridge University Press, pp. 247-262.

Kawasaki, G., 2012. Enchantment: The Art of Changing Hearts, Minds, and Actions. New York: Portfolio.

Kleinman, E. \& Dwyer, F. M., 1999. Analysis of computerized visual skills: relationships to intellectual skills and achievement. International Journal of Instructional Media, 26(1), pp. 53-69.

Kosslyn, S., 2007. Clear and to the Point : 8 Psychological Principles for Compelling. New York: Oxford University Press .

Largent, E., Grady, C. \& Miller, , F. G., 2012. Money, coercion, and undue inducement: a survey of attitudes about payments to research participants. Institutional Review Board, 34(1), pp. 1-8.

Levin, J., 1981. On functions of pictures in prose. In: Neuropsychological and Cognitive Processes in Reading. New York: Academic Press, pp. 203-228.

Lewis, P., 2016. Brain Friendly Teaching-Reducing Learner's Cognitive Load. Academic Radiology, 23(7), pp. 877-880.

Little, D., Felten, P. \& Berry, C., 2010. Liberal Education in a Visual World. Liberal Education, 96(2), p. 44-49..

Mayer, R., 2014. The Cambridge Handbook of Multimedia Learning. 2nd ed. New York: Cambridge University Press.

Mayer, R. \& Moreno, M., 2003. Nine Ways to Reduce Cognitive Load in Multimedia Learning. Educational Psychologist, 38(1), pp. 43-52.

Mayer, R. \& Moreno, R., 1998. A split-attention effect in multimedia learning: Evidence for dual processing systems in working memory. Journal of Educational Psychology,, 90(2), pp. 312-320.

Mayer, R. \& Sims, V. K., 1994. For whom is a picture worth a thousand words? Extensions of a dualcoding theory of multimedia learning.. Journal of Educational Psychology, 86(3), pp. 389-401.

McBride, D. \& Dosher, B. A., 2002. A comparison of conscious and automatic memory processes for picture and word stimuli: a process dissociation analysis. Consciousness and Cognition, Volume 11, pp. 423-460. 
McKay, E., 1999. An investigation of text-based instructional materials enhanced with graphics. Educational Psychology, 19(3), pp. 323-335.

McQuarrie, E. \& Mick, D., 1999. Visual rhetoric in advertising: Text-interpretive, experimental, and reader-response analyses. Journal of Consumer Research, 26(1), pp. 37-54.

McStay, A., 2013. Creativity and Advertising: Affect, Events and Process. London: Routledge.

Meira, L., Pliskina , N. \& Gilad , R., 2010. Studying decision processes via a knowledge management lens: The Columbia space shuttle case. Decision Support Systems, 48(4), p. 559-567.

Messaris, P., 1994. Visual "literacy": Image, mind, and reality. Boulder: Westview Press.

Oblinger, D. \& Oblinger, J. L., 2005. Educating the net generation. [Online]

Available at: https://www.google.co.uk/search?q=Educating+the+net+generation\&ie=utf-8\&oe=utf8\&gws $r d=c r \& e i=S o 5 o V e W S H 4 f Z y A P u l Y F Q$

[Accessed 29 May 2015].

Paivio, A., 1971. Imagery and verbal processes. New York: Holt, Rinehart, and Winston.

Paivio, A., 1986. Paivio, A Mental representations: a dual coding approach. Oxford: Oxford University Press.

Paivio, A., 2007. Mind and its evolution: A dual coding theoretical approach. Mahwah, NJ: Erlbaum. Paivio, A. \& Clark, J. M., 1991. Dual-Coding Theory and Education. Educational Psychology Review, 3(3).

Robinson, N., 1999. The use of focus group methodology with selected examples from sexual health research. Journal of Advanced Nursing, 29(4), pp. 905-913.

Schrand, T., 2008. Tapping into active learning and multiple intelligences with interactive multimedia: a low-threshold classroom approach. College Teaching, 56(2), pp. 78-84.

Siegel, L. \& Ryan, E. B., 1989. The Development of Working Memory in Normally Achieving and Subtypes of Learning Disabled Children. Child Development, 60(4), pp. 973-980.

Singer, E., 2003. Exploring the meaning of consent: participation in research and beliefs about risks and benefits. Journal of Official Statistics, 19(3), p. 273-285.

Singer, E. \& Ye, C., 2013. The Use and Effects of Incentives in Surveys. The Annals of the American Academy of Political and Social Science, 645(1), pp. 112-141.

Sonderholm, J., 2010. A Reform Proposal in Need of Reform: A Critique of Thomas Pogge's Proposal for How to Incentivize Research and Development of Essential Drugs. Public Health Ethics, 36(2), pp. 167-177.

Stewart, D. W. \& Shamdesani, P. M., 2014. Focus Groups: Theory and Practice. London: Sage.

Sweller, J., Ayers, P. \& Kalyuga, S., 2011. Cognitive Load Theory. London: Springer.

Thompson, C., 2003. PowerPoint makes you dumb, New York: s.n. 
Tietje, L. \& Cresap, S., 2005. Radical Pedagogy. [Online]

Available at: http://www.radicalpedagogy.org/radicalpedagogy.org/Hegemonic Visualism.html [Accessed 18 May 2015].

Trowler, V., 2010. Student engagement literature review. London: Higher Education Academy.

Tuckey, H. \& Selvaratnam, M., 1993. Studies involving three-dimensional visualization skills in chemistry: a review. Studies in Science Education, 21(1), pp. 99-121.

Tufte, E., 2015. The Work of Edward Tufte and Graphics Press. [Online]

Available at: http://www.edwardtufte.com/bboard/q-and-a-fetch-msg?msg id=0003mW

[Accessed 5 August 2015].

Wendler, D., Rackoff, J. E., Emanuel, E. J. \& Grady, C., 2002. The ethics of paying for children's participation in research. Journal of Pediatrics, 141(2), p. 166-171.

Wilkinson, S., 1998. Focus group methodology: a review. International Journal of Social Research Methodology, 1(3), pp. 181-203.

Williams, V., 1998. Creating Effective Visual Metaphors. [Online]

Available at:

http://www.google.co.uk/url?sa=t\& $r c t=i \& q=\& e s r c=s \&$ source=web\&cd=5\&ved=0CDUQFjAE\&url=http \%3A\%2F\%2Fwww.personal.psu.edu\%2Fstaff\%2Fv\%2Fq\%2Fvqw\%2FPortfolio\%2FVisIMeta.pdf\&ei=FxZi Ve7IC8GsU9vhgfgG\&usg=AFQjCNFfV8D7xsu5KYjhTjsDKwkVHRY-Ow\&sig2=tqITHQIMMa anqDQfX5Lf [Accessed 24 May 2015].

Yu, A., 2014. Physicists, Generals And CEOs Agree: Ditch The PowerPoint. [Online] Available at: http://www.npr.org/sections/alltechconsidered/2014/03/16/288796805/physicistsgenerals-and-ceos-agree-ditch-the-powerpoint [Accessed 18 May 2015].

Yue, C., Bjork, E. L. \& Bjork, R. A., 2013. Reducing verbal redundancy in multimedia learning: An undesired desirable difficulty?. Journal of Educational Psychology, 105(2), pp. 266-277. 


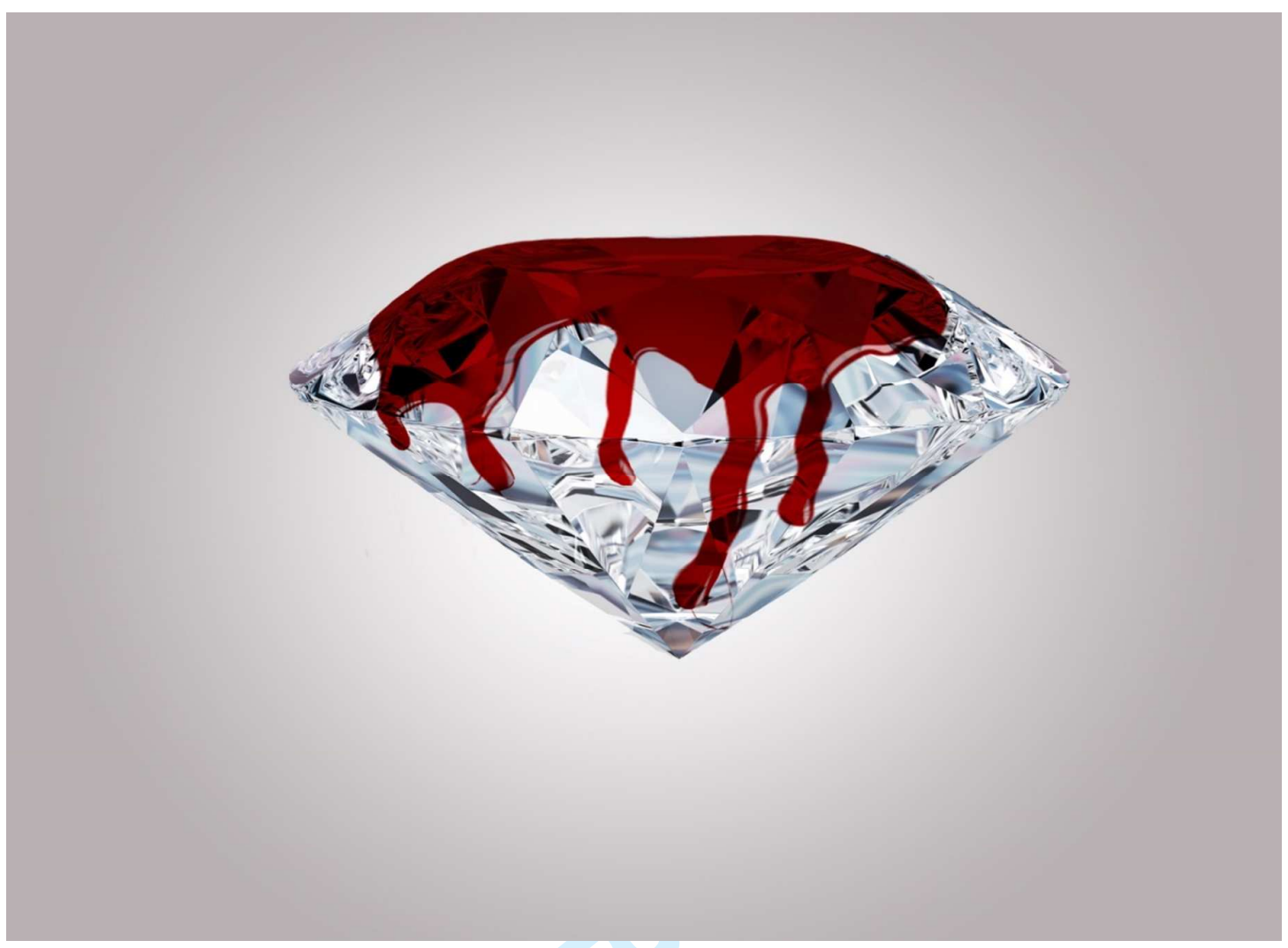

Image 1 Blood diamond 


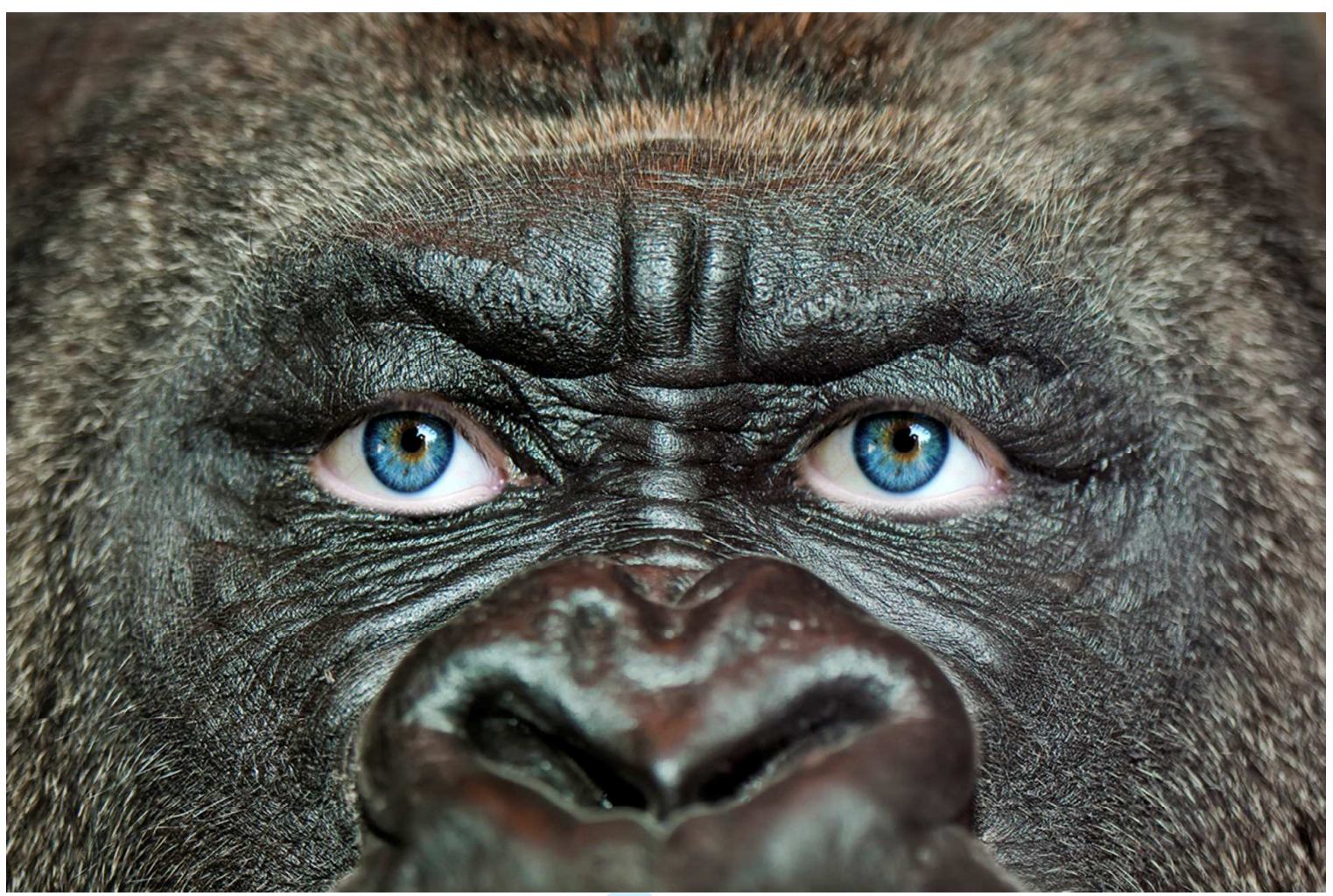

Image 2 Ape-man.

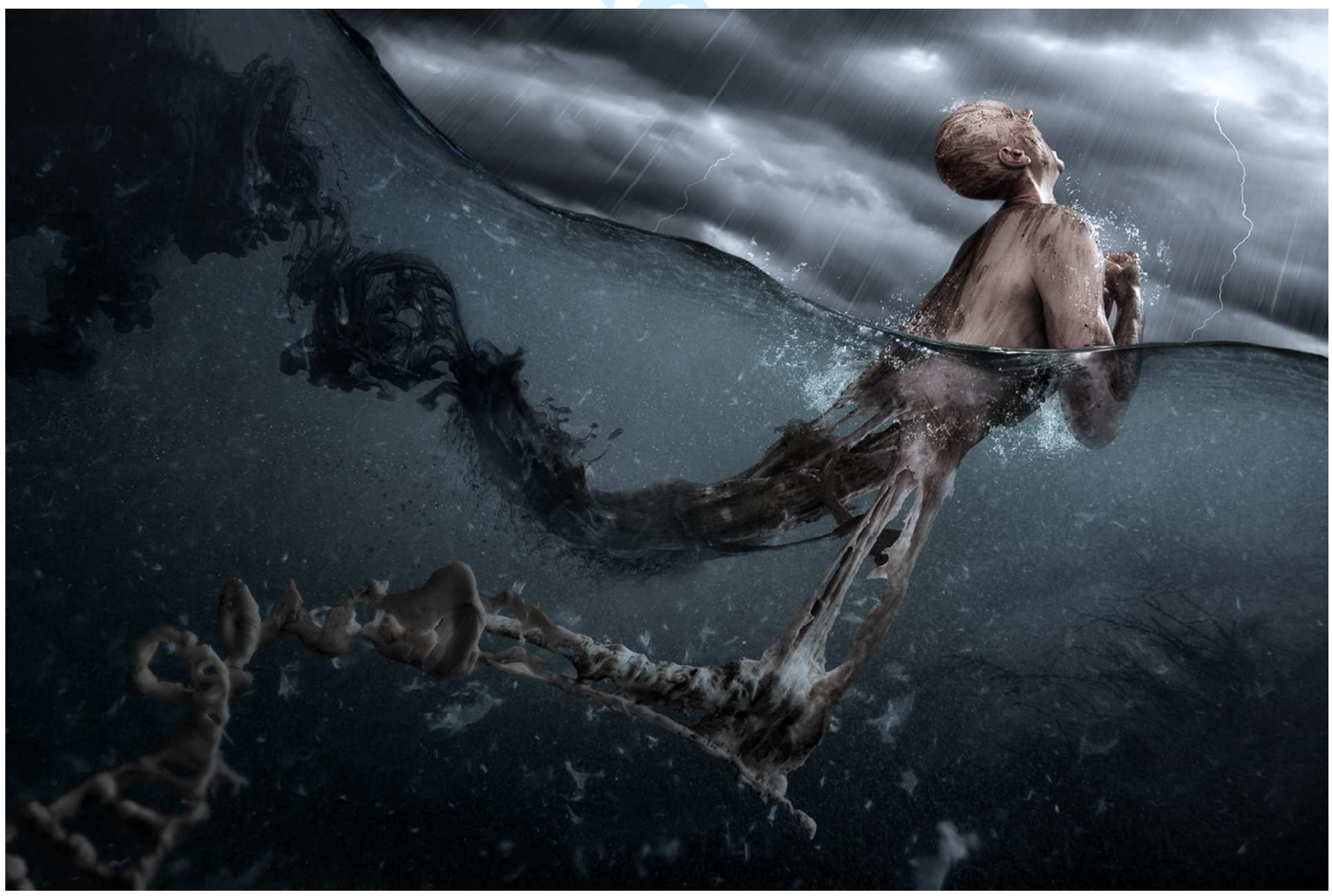

Image 3 Evolution. 


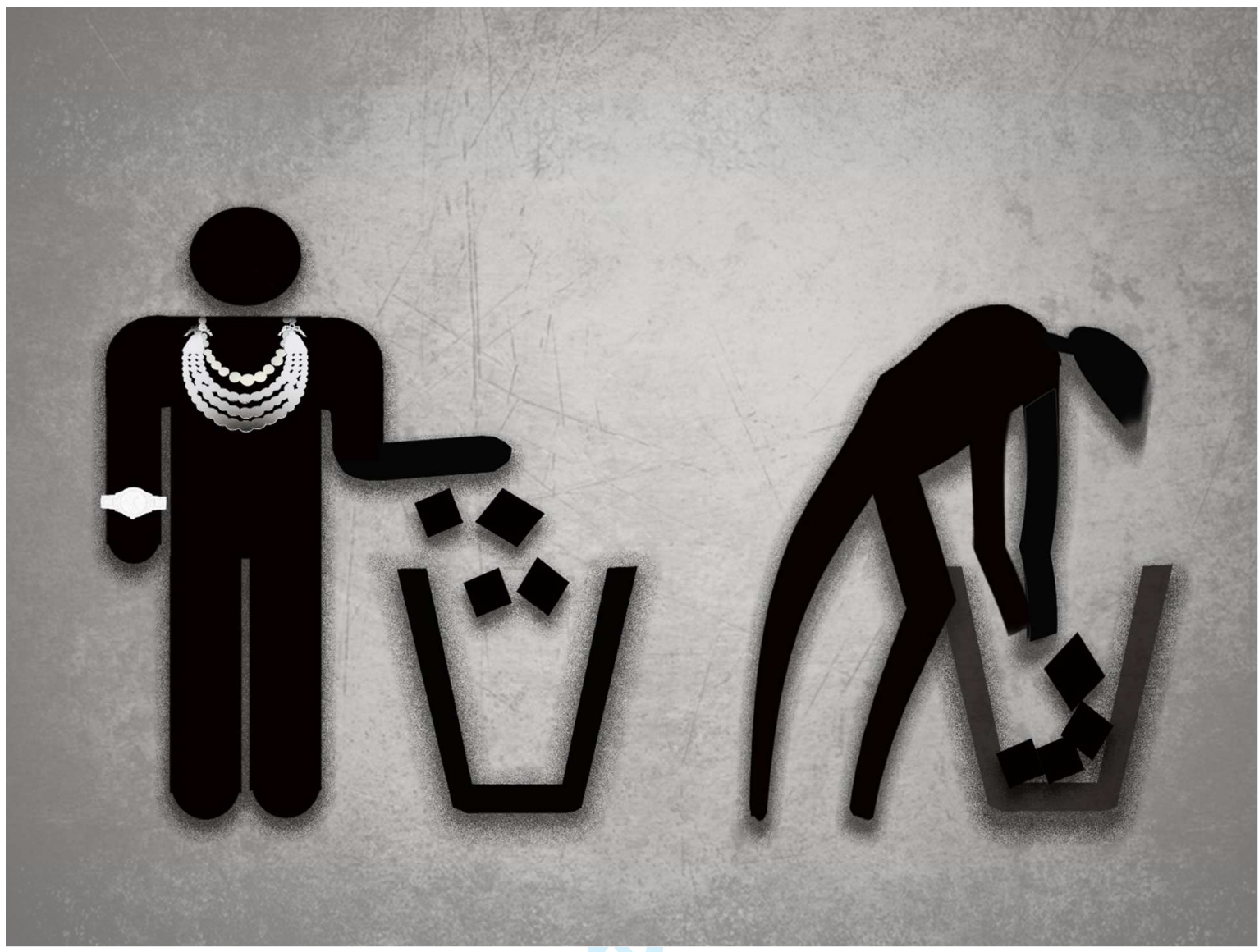

Image 4 Inequality. 


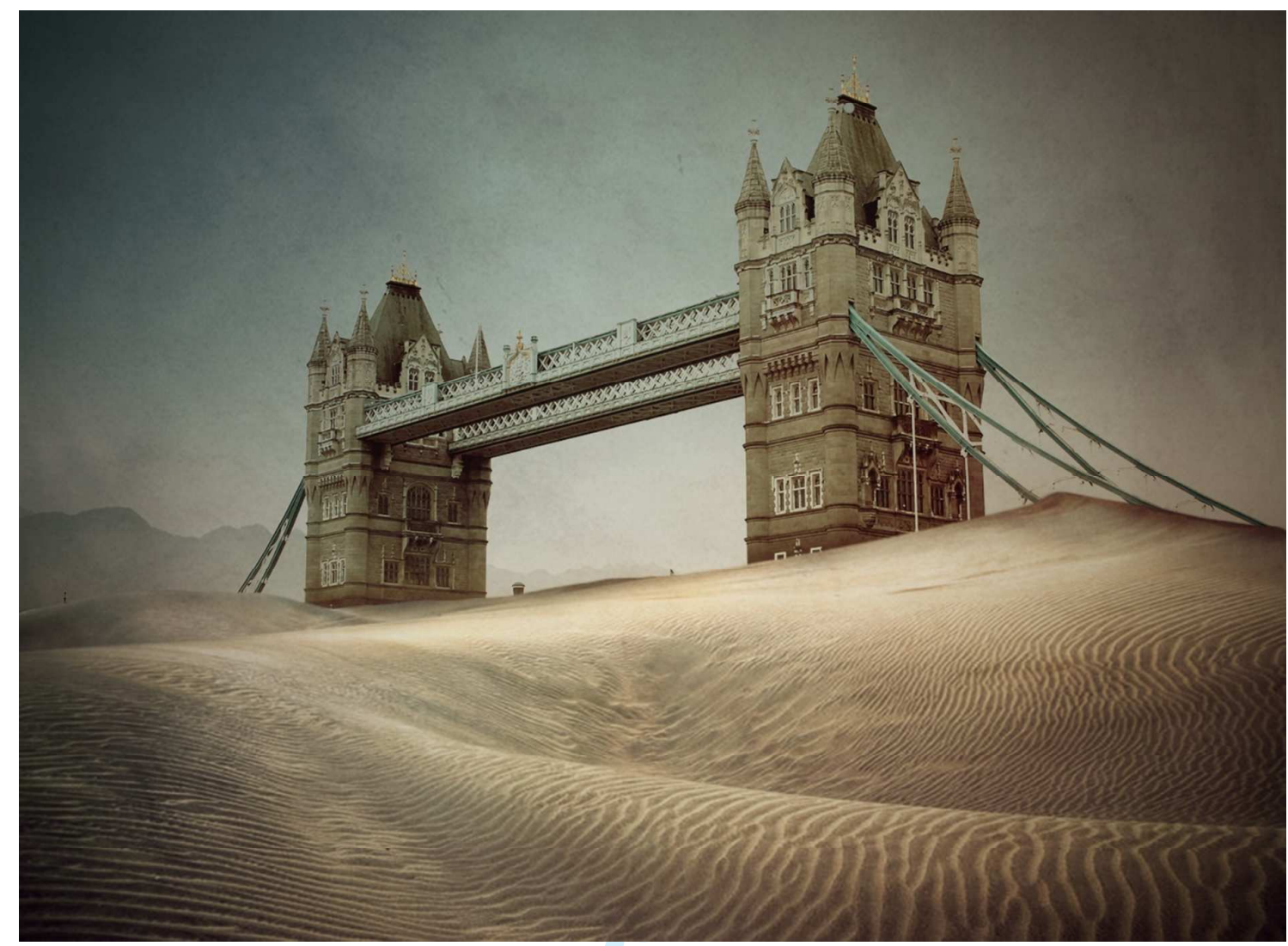

Image 5 Desertification 


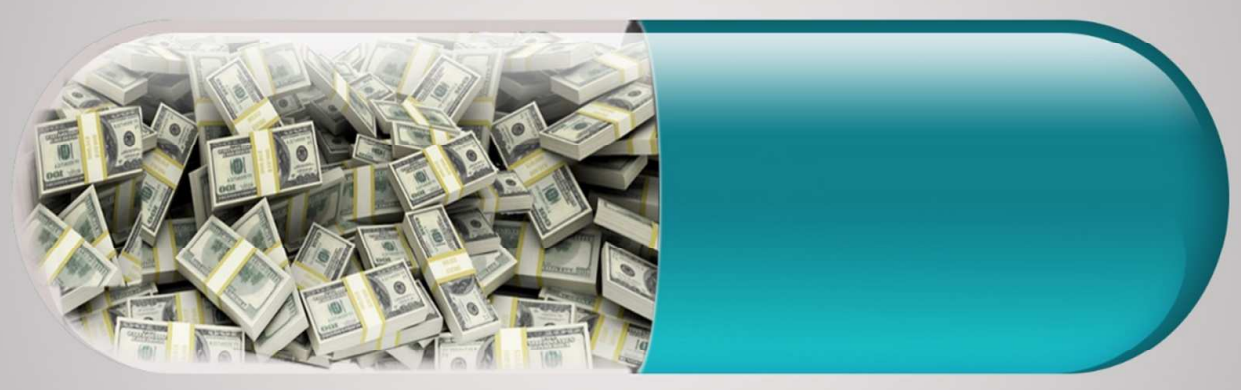

Image 6 Cash pill 


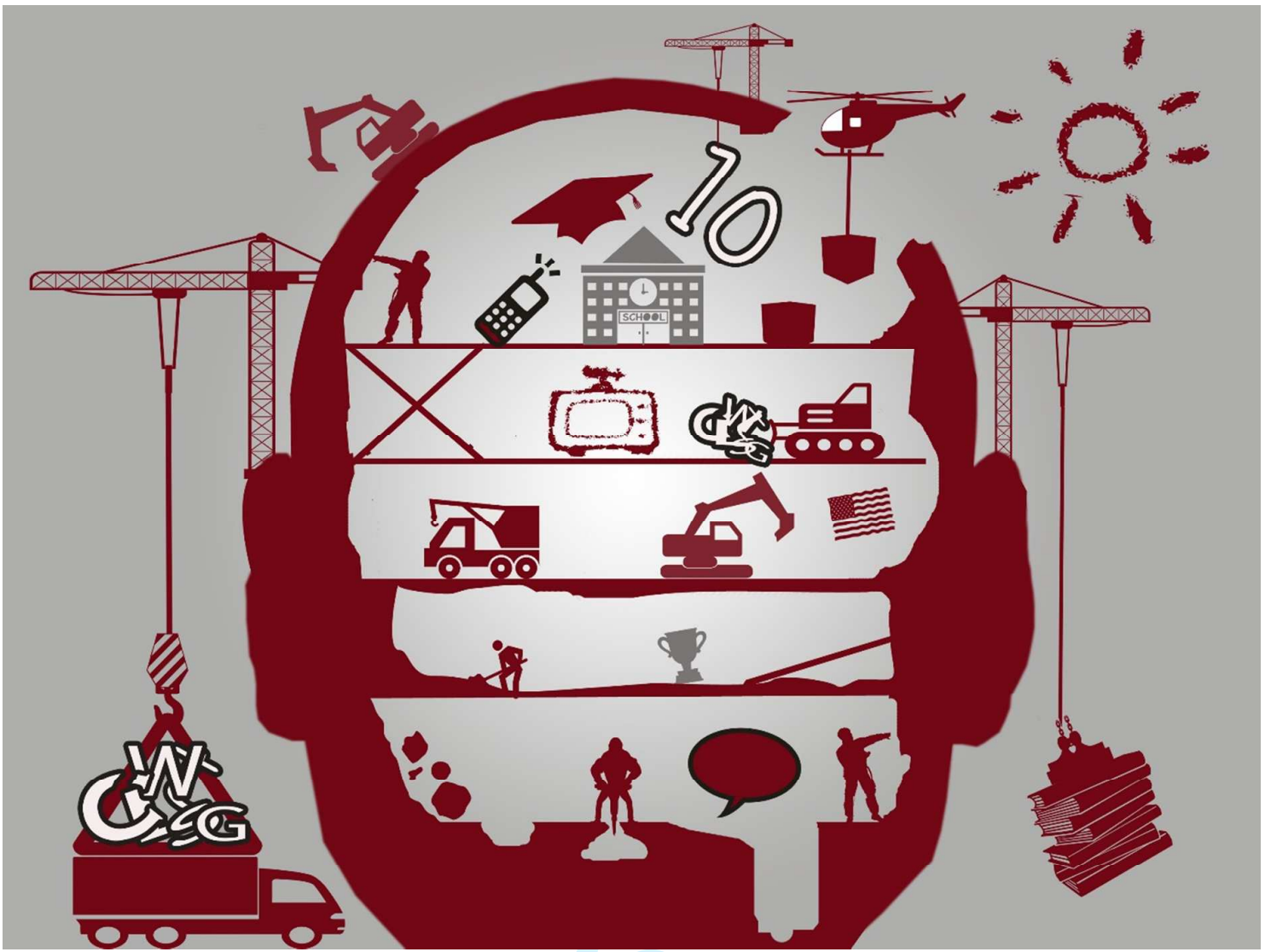

Image 7 social construction of the mind 


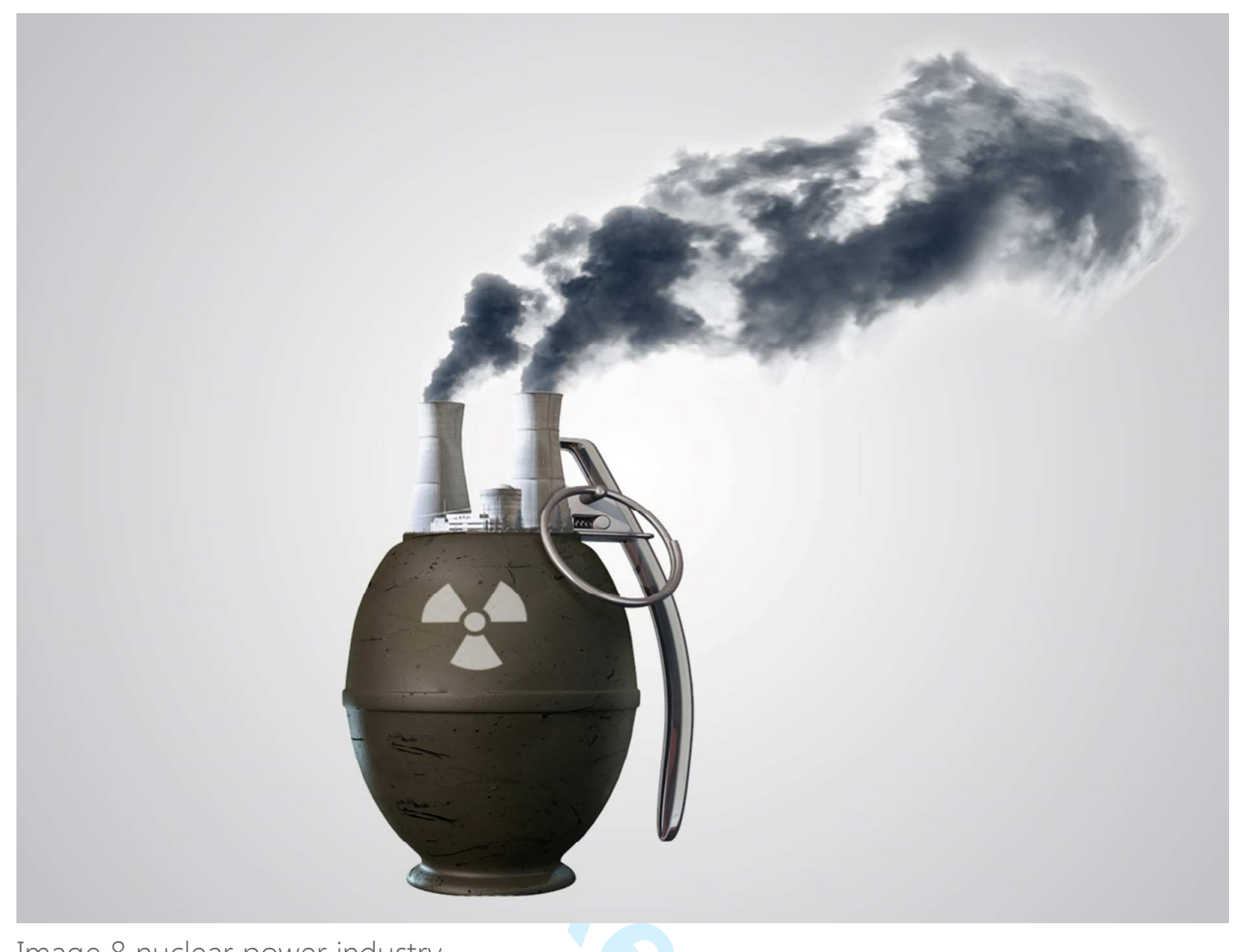

Image 8 nuclear power industry 


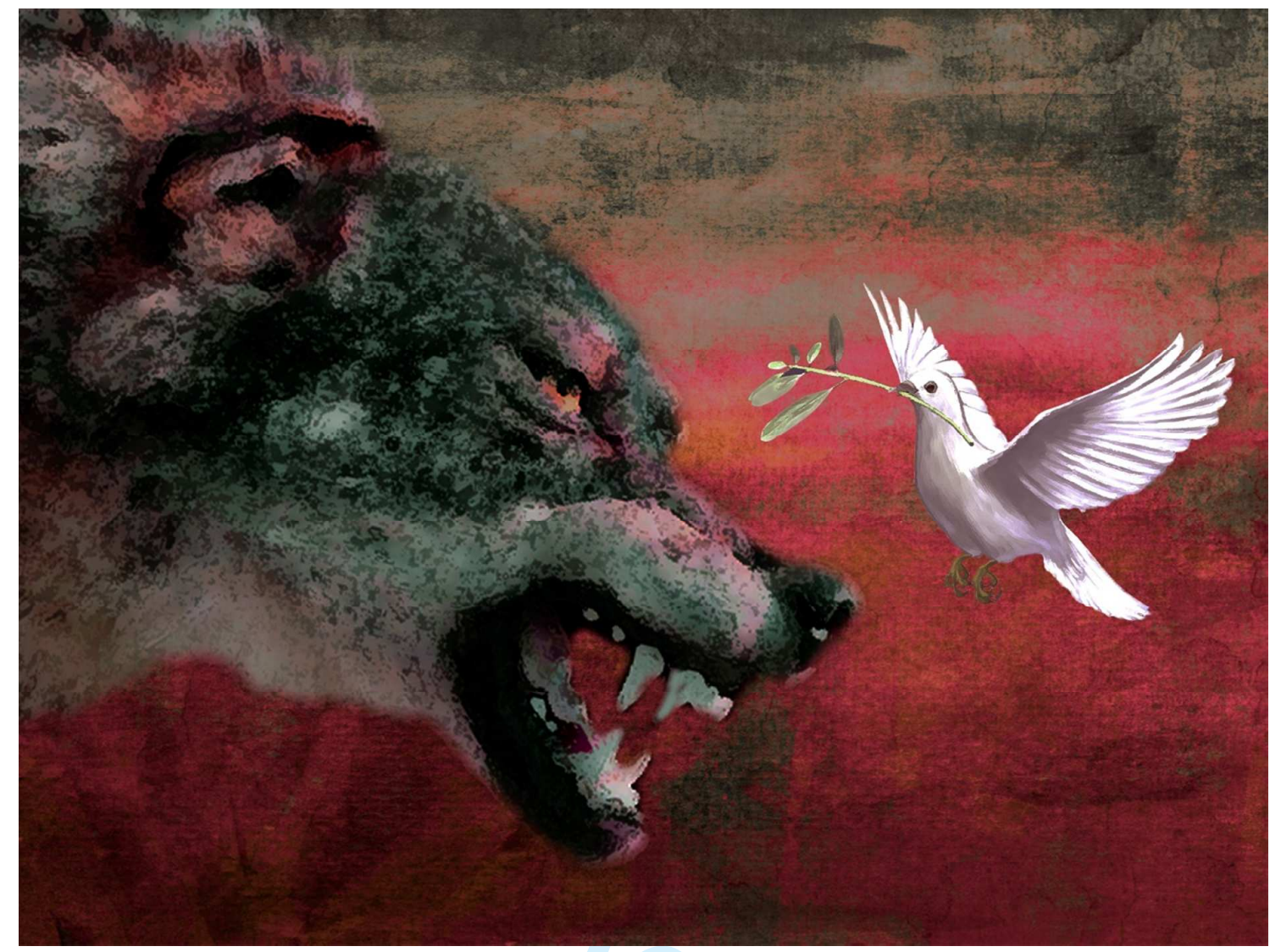

Image 9 peace and war ontologies 
100
Table 1: quantitative survey responses 2014.

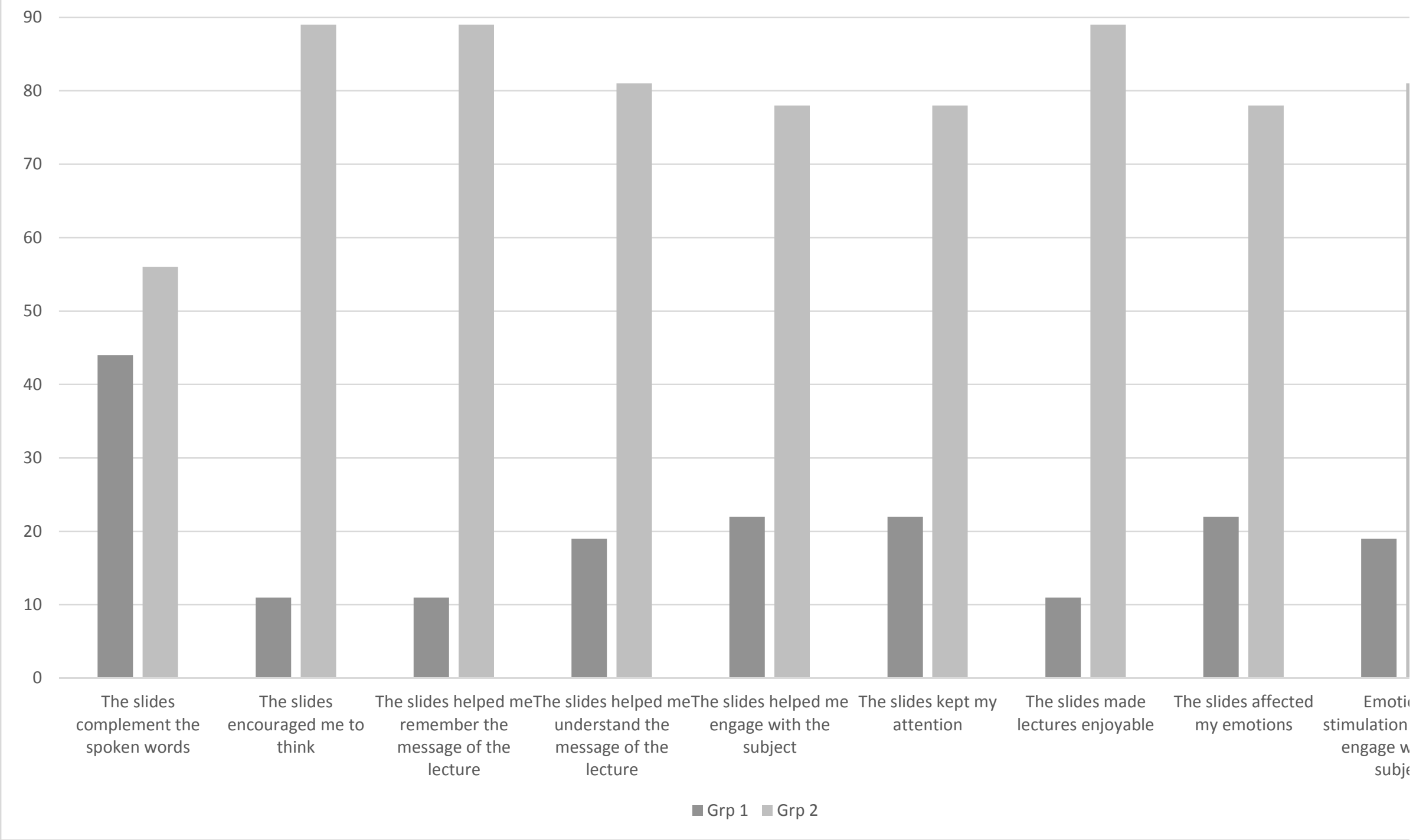


Table 2: quantitative survey responses 2015.

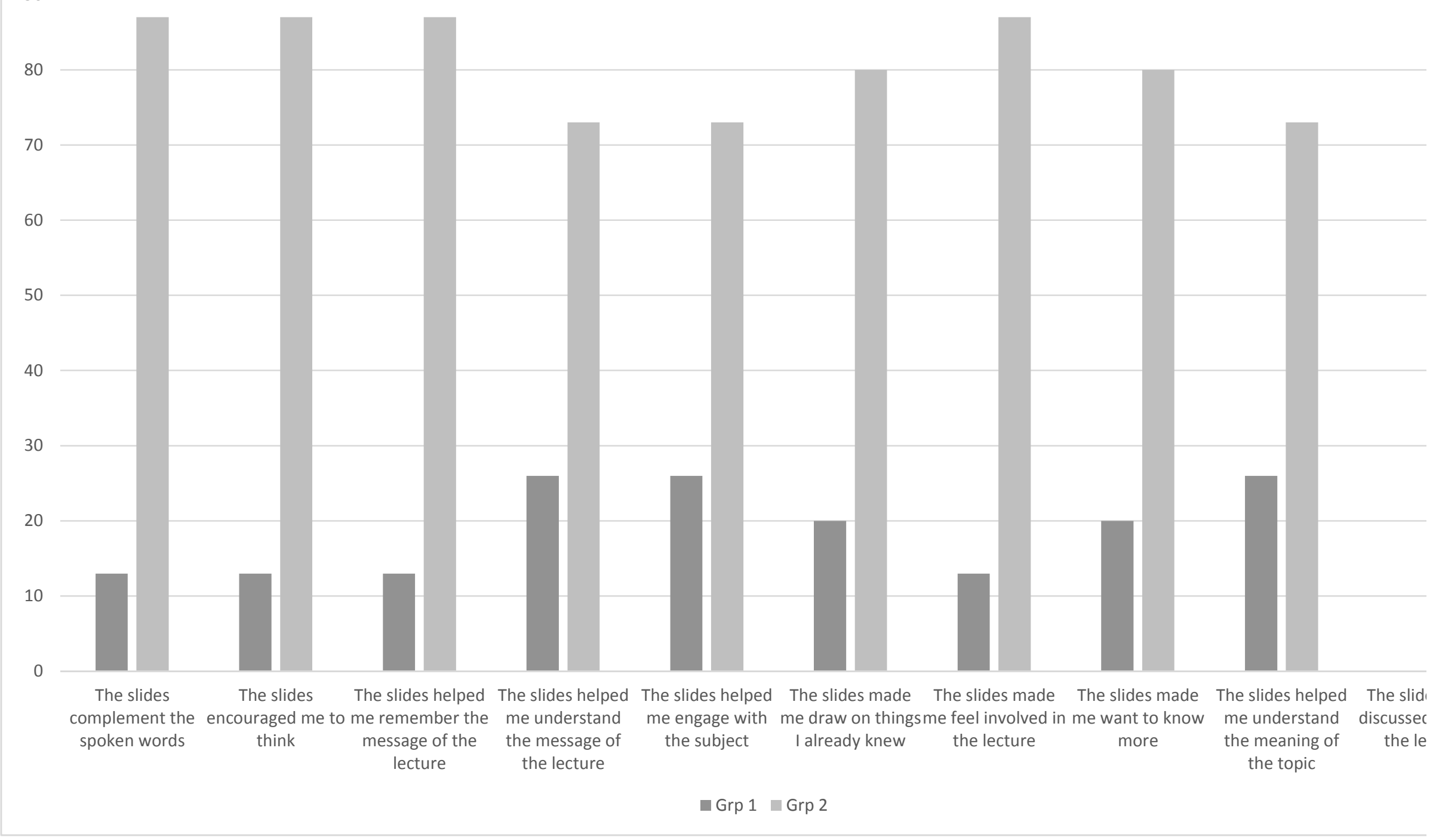




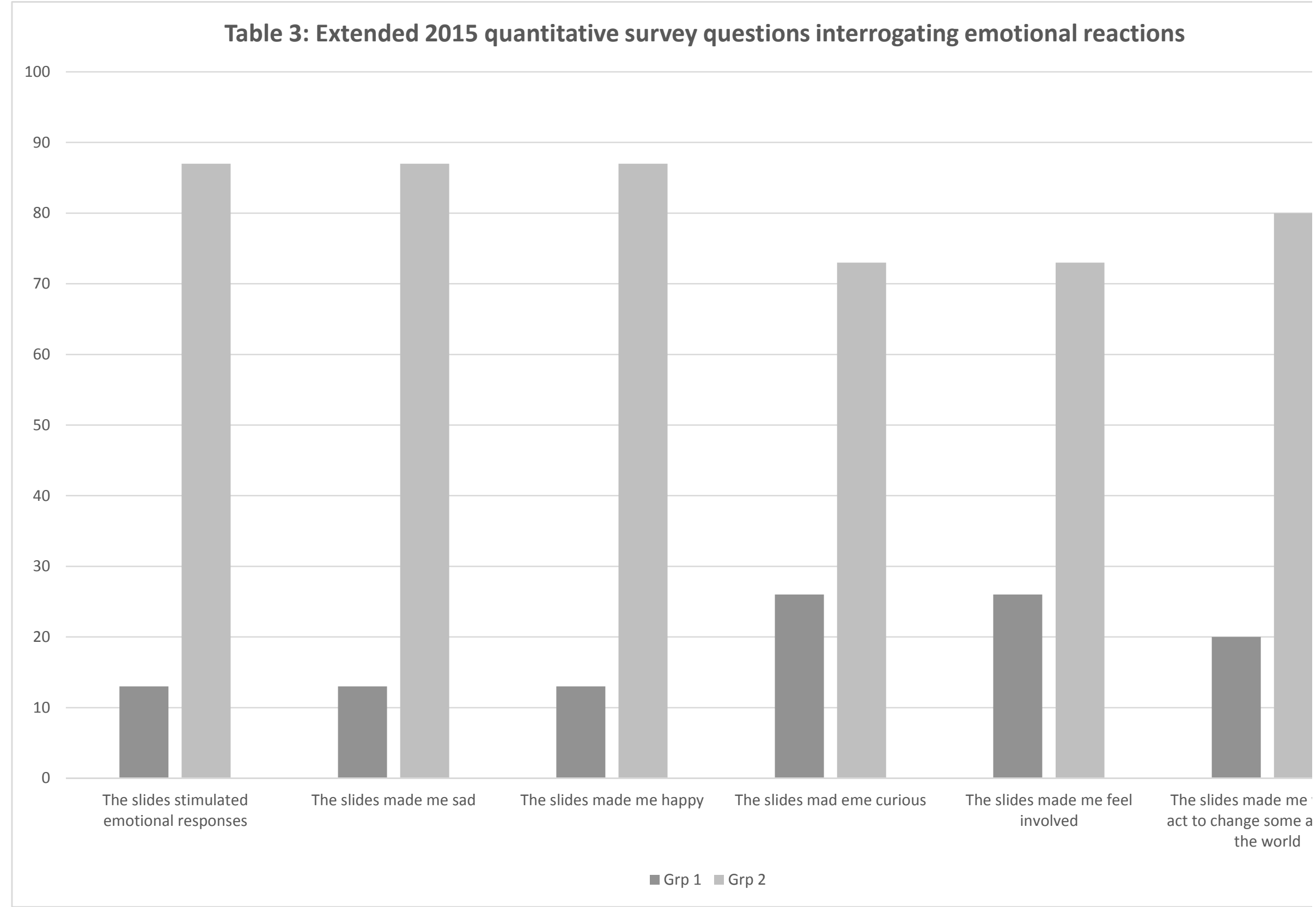

URL: http://mc.manuscriptcentral.com/cjfh 


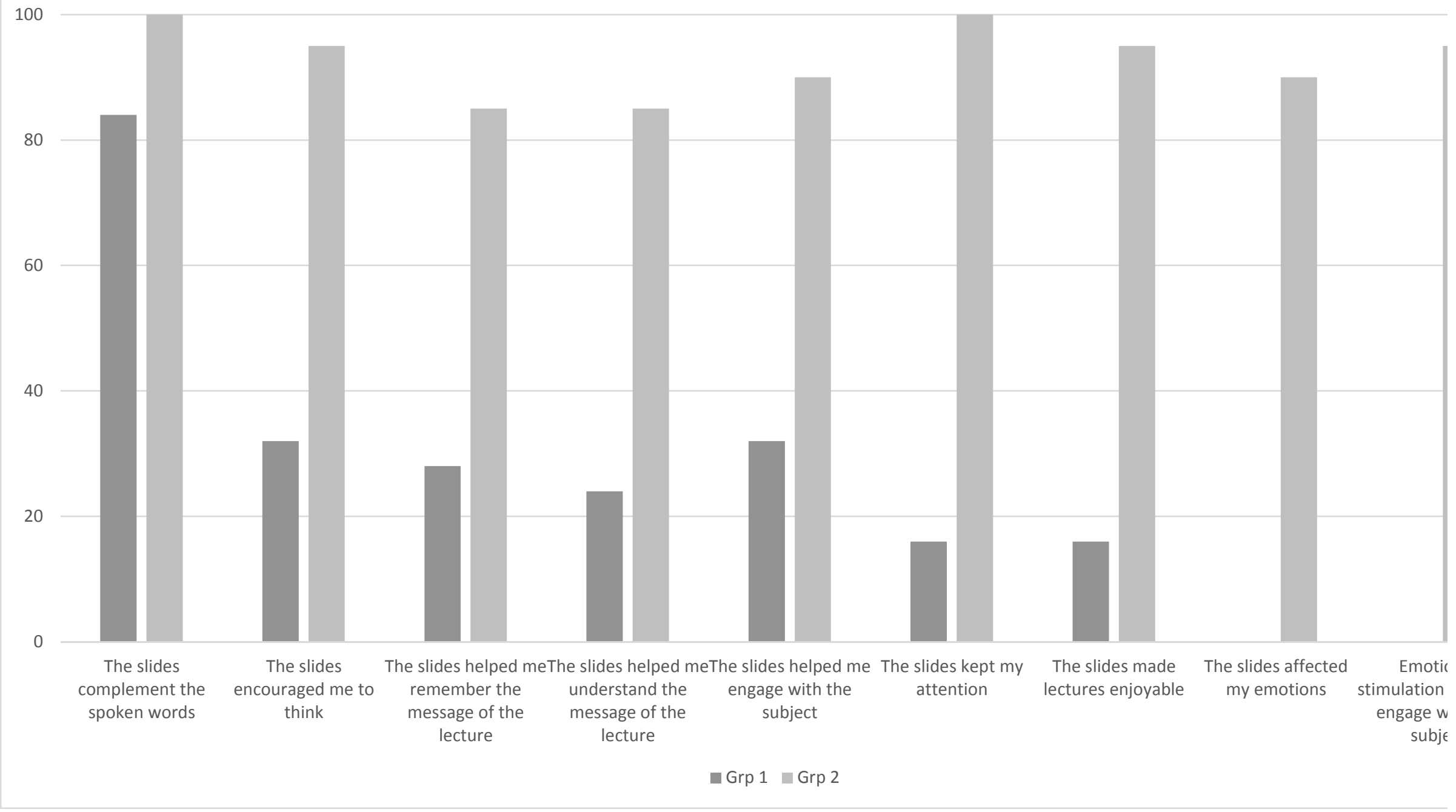

